\section{CORRECTION}

View Article Online

View Journal I View Issue

\section{(A) Check for updates}

Cite this: Food Funct., 2021, 12, 6117

\title{
Correction: Tracking physical breakdown of rice- and wheat-based foods with varying structures during gastric digestion and its influence on gastric emptying in a growing pig model
}

\author{
Joanna Nadia, a,b Alexander G. Olenskyj, ${ }^{c}$ Natascha Stroebinger, ${ }^{b}$ \\ Suzanne M. Hodgkinson, ${ }^{\text {b }}$ Talia G. Estevez, ${ }^{c}$ Parthasarathi Subramanian, ${ }^{b}$ \\ Harjinder Singh, ${ }^{\mathrm{b}}$ R. Paul Singh ${ }^{\mathrm{b}, \mathrm{c}}$ and Gail M. Bornhorst ${ }^{\star b, c}$ \\ Correction for 'Tracking physical breakdown of rice- and wheat-based foods with varying structures \\ during gastric digestion and its influence on gastric emptying in a growing pig model' by Joanna Nadia \\ et al., Food Funct., 2021, DOI: 10.1039/DOFO02917C.
}

DOI: 10.1039/d1fo90045e

rsc.li/food-function

The authors regret that there was an error in the calculation of dry matter gastric emptying affecting both Fig. 5 and Table 6 . This error does not affect a significant portion of the data in the article, only a single parameter, and does not change the trends or interpretation of the data. The correct version of Fig. 5 and Table 6 are given below.

\footnotetext{
${ }^{a}$ School of Food and Advanced Technology, Massey University, Private Bag 11222, Palmerston North, New Zealand

${ }^{b}$ Riddet Institute, Massey University, Private Bag 11222, Palmerston North, New Zealand

${ }^{c}$ Department of Biological and Agricultural Engineering, University of California, Davis, CA 95618, USA. E-mail: gbornhorst@ucdavis.edu
} 
(A) Dry matter gastric emptying, wheat-based diets

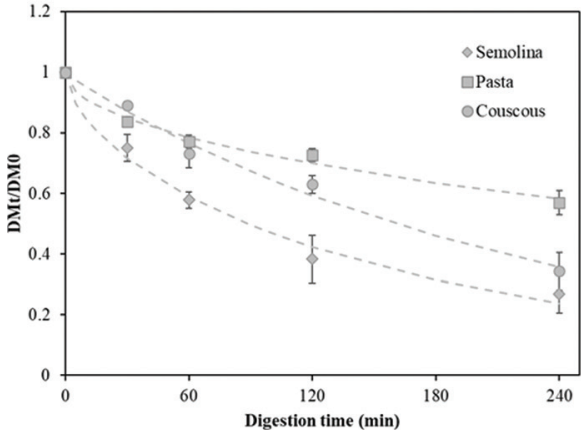

(C) Dry matter gastric emptying, rice-based diets

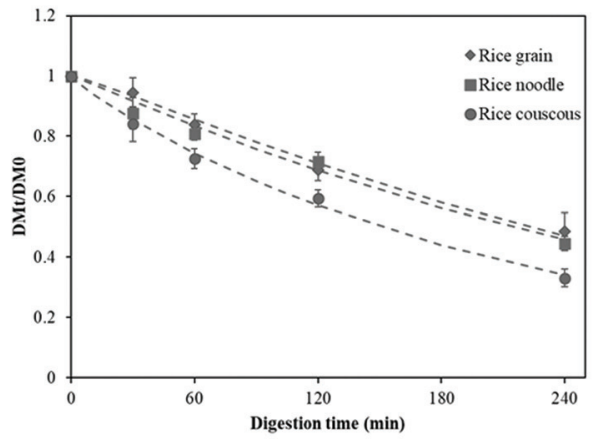

(E) Gastric emptying - diet initial size relationship

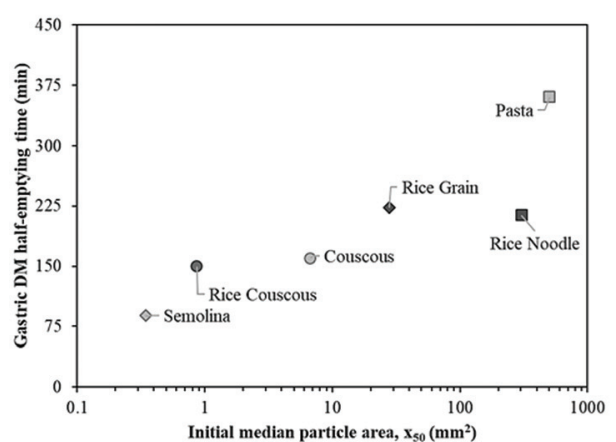

(B) Whole stomach content emptying, wheat-based diets

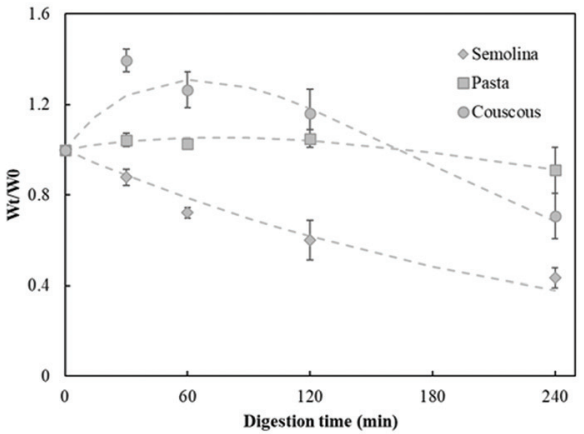

(D) Whole stomach content emptying, rice-based diets

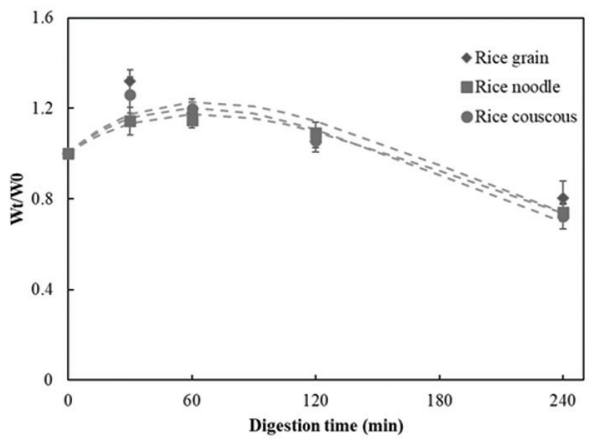

(F) Gastric emptying - gastric breakdown rate relationship

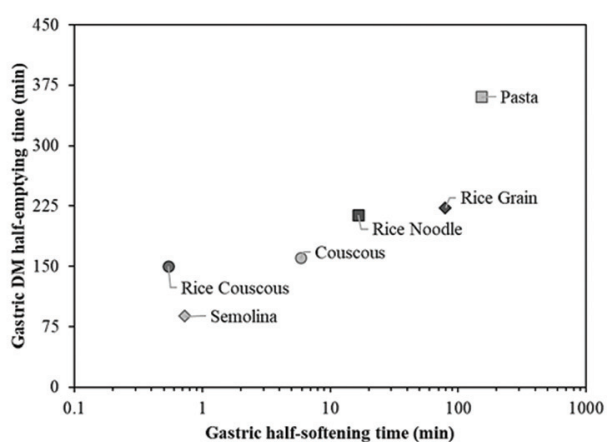

Fig. 5 Gastric emptying of dry matter ( $A$ and $C$ ) and whole stomach content (B and $D)$ of pigs fed with wheat-based diets (A and B) or rice-based diets (C and D) during 240 min of digestion. Points represent measured values (mean \pm SEM $n \geq 5$ for each diet $\times$ time, except rice grain $\times 60$ min $(n=4)$ ). Dashed lines represent the predicted dry matter gastric emptying profile based on modified exponential model (eqn (2)) or predicted total meal gastric emptying profile based on linear-exponential model (eqn (3)). Dry matter half-emptying times from (A) and (C) were plotted against initial median particle area (E) of the cooked diets or gastric softening half-time (F). Gastric softening half-time for each diet was represented by the longest softening half-time between the proximal and distal stomach regions for each diet. Note that the $x$-axis for (E) and (F) is shown on a logscale due to the wide range of the values across the six diets. 
Table 6 Gastric emptying parameters (expressed as predicted parameter $\pm 95 \%$ confidence interval) and predicted emptying half-time of dry matter and whole stomach content. Note that the confidence interval for $k_{\text {whole }}$ and $\beta_{\text {whole }}$ of semolina was very wide due to the lack of initial increase in its $W_{t} / W_{0}$ profile (Fig. $5 B$ ) that was supposed to be predicted by the linear-exponential model. Despite the wide confidence interval, the linear-exponential model still fit well to the data

Dry matter gastric emptying (predicted with modified-exponential model, eqn (2))

\begin{tabular}{lllll}
\hline & \multicolumn{2}{l}{ Gastric emptying parameter } & & \\
\cline { 2 - 5 } Diet & $k_{\mathrm{DM}} \times 10^{3}\left(\mathrm{~min}^{-1}\right)$ & $\beta_{\mathrm{DM}}($ dimensionless $)$ & 0.75 & \multicolumn{1}{c}{$\begin{array}{c}\text { Emptying half-time, } \\
t_{1 / 2, \mathrm{DM} \mathrm{GE}}(\mathrm{min})\end{array}$} \\
\hline Semolina & $4.14 \pm 3.12$ & $0.59 \pm 0.32$ & 0.82 & 88 \\
Couscous & $4.16 \pm 2.18$ & $0.96 \pm 0.42$ & 0.79 & 360 \\
Pasta & $0.81 \pm 0.73$ & $0.50 \pm 0.18$ & 0.80 & 223 \\
Rice grain & $3.72 \pm 2.20$ & $1.21 \pm 0.62$ & 0.87 & 150 \\
Rice couscous & $4.13 \pm 1.75$ & $0.90 \pm 0.32$ & 0.89 & 213 \\
Rice noodle & $3.51 \pm 1.34$ & $1.09 \pm 0.35$ & & $R^{2}$ \\
\hline
\end{tabular}

Whole stomach content gastric emptying (predicted with linear-exponential model, eqn (3))

\begin{tabular}{|c|c|c|c|c|}
\hline \multirow[b]{2}{*}{ Diet } & \multicolumn{2}{|c|}{ Gastric emptying parameter } & \multirow[b]{2}{*}{$R^{2}$} & \multirow{2}{*}{$\begin{array}{l}\text { Emptying half-time, } \\
t_{1 / 2, \text { whole GE }}(\mathrm{min})\end{array}$} \\
\hline & $k_{\text {whole }}$ (dimensionless) & $\beta_{\text {whole }}\left(\times 10^{3} \min ^{-1}\right)$ & & \\
\hline Semolina & $0.009 \pm 204.09$ & $4.04 \pm 832.98$ & 0.65 & 173 \\
\hline Couscous & $2.38 \pm 0.39$ & $9.38 \pm 2.04$ & 0.61 & 288 \\
\hline Pasta & $1.40 \pm 0.35$ & $3.81 \pm 2.10$ & 0.18 & 536 \\
\hline Rice grain & $2.06 \pm 0.33$ & $7.88 \pm 1.72$ & 0.54 & 319 \\
\hline Rice couscous & $2.01 \pm 0.29$ & $8.21 \pm 1.49$ & 0.70 & 302 \\
\hline Rice noodle & $1.84 \pm 0.21$ & $7.21 \pm 1.08$ & 0.78 & 329 \\
\hline
\end{tabular}

The Royal Society of Chemistry apologises for these errors and any consequent inconvenience to authors and readers. 